\title{
High time-resolved measurement of stable carbon isotope composition in water-soluble organic aerosols: method optimization and a case study during winter haze in eastern China
}

Wenqi Zhang et al.

Correspondence to: Yan-Lin Zhang (dryanlinzhang@outlook.com)

The copyright of individual parts of the supplement might differ from the CC BY 4.0 License. 
17 Pages

21 Table

35 Figures

4 Table S1. Statistical results of isotope compositions after different heating time.

\begin{tabular}{|c|c|c|c|c|}
\hline Heating time & Carbon content & Average $\delta^{13} \mathrm{C}$ & $\mathrm{SD}(\mathrm{n}=5)$ & Total SD \\
\hline \multirow{5}{*}{15} & 0 & -32.01 & & \multirow{5}{*}{0.53} \\
\hline & 4 & -28.86 & 0.24 & \\
\hline & & & & \\
\hline & 10 & -29.77 & 0.13 & \\
\hline & 30 & -30.00 & 0.02 & \\
\hline \multirow{5}{*}{30} & 0 & -32.50 & & \multirow{5}{*}{0.57} \\
\hline & 4 & -28.92 & 0.53 & \\
\hline & & & & \\
\hline & 10 & -29.71 & 0.09 & \\
\hline & 30 & -30.04 & 0.08 & \\
\hline \multirow{5}{*}{60} & 0 & -31.03 & & \multirow{5}{*}{0.51} \\
\hline & 4 & -29.04 & 0.59 & \\
\hline & & & & \\
\hline & 10 & -29.71 & 0.10 & \\
\hline & 30 & -29.96 & 0.05 & \\
\hline \multirow{5}{*}{90} & 0 & -32.47 & & \multirow{5}{*}{0.71} \\
\hline & 4 & -28.77 & 0.22 & \\
\hline & & & & \\
\hline & 10 & -29.85 & 0.28 & \\
\hline & 30 & -29.39 & 0.94 & \\
\hline \multirow{5}{*}{120} & 0 & -29.13 & & \multirow{5}{*}{4.58} \\
\hline & 4 & -28.59 & 0.21 & \\
\hline & & & & \\
\hline & 4 & -26.42 & 6.46 & \\
\hline & 30 & -27.30 & 5.34 & \\
\hline
\end{tabular}

5 


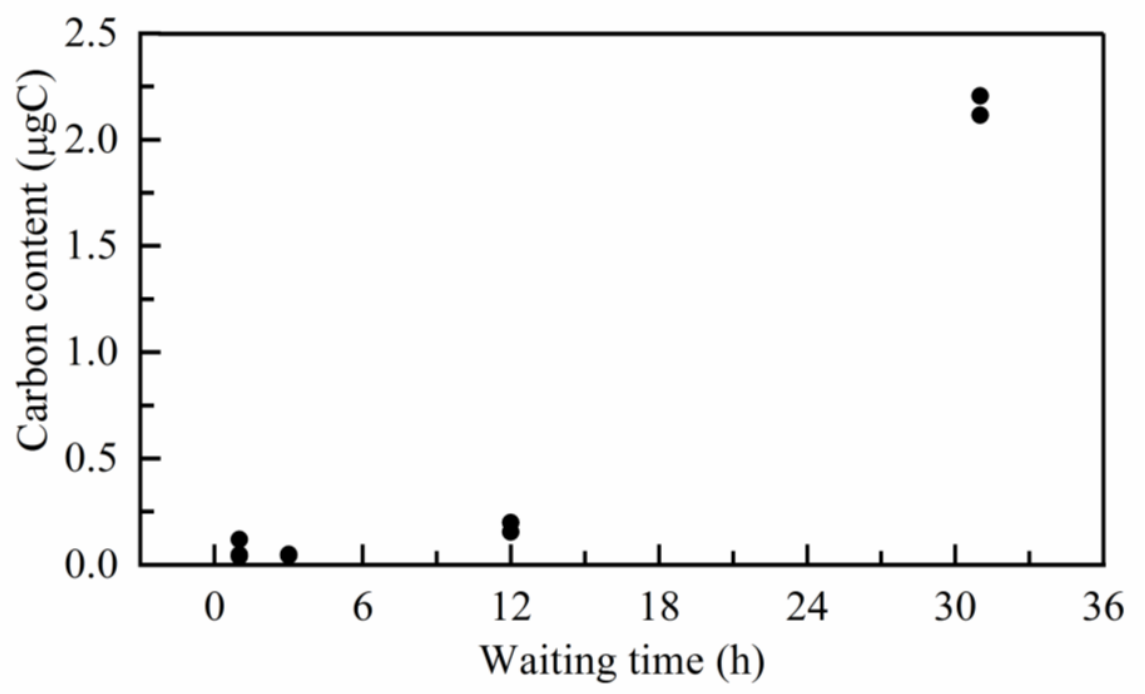

7 Figure S1. Carbon contents of one ambient aerosol sample replicates tested after different

8 waiting time (duration between the mixture of aerosol extractions with the oxidizing solution and the helium flushing step) without heating. 


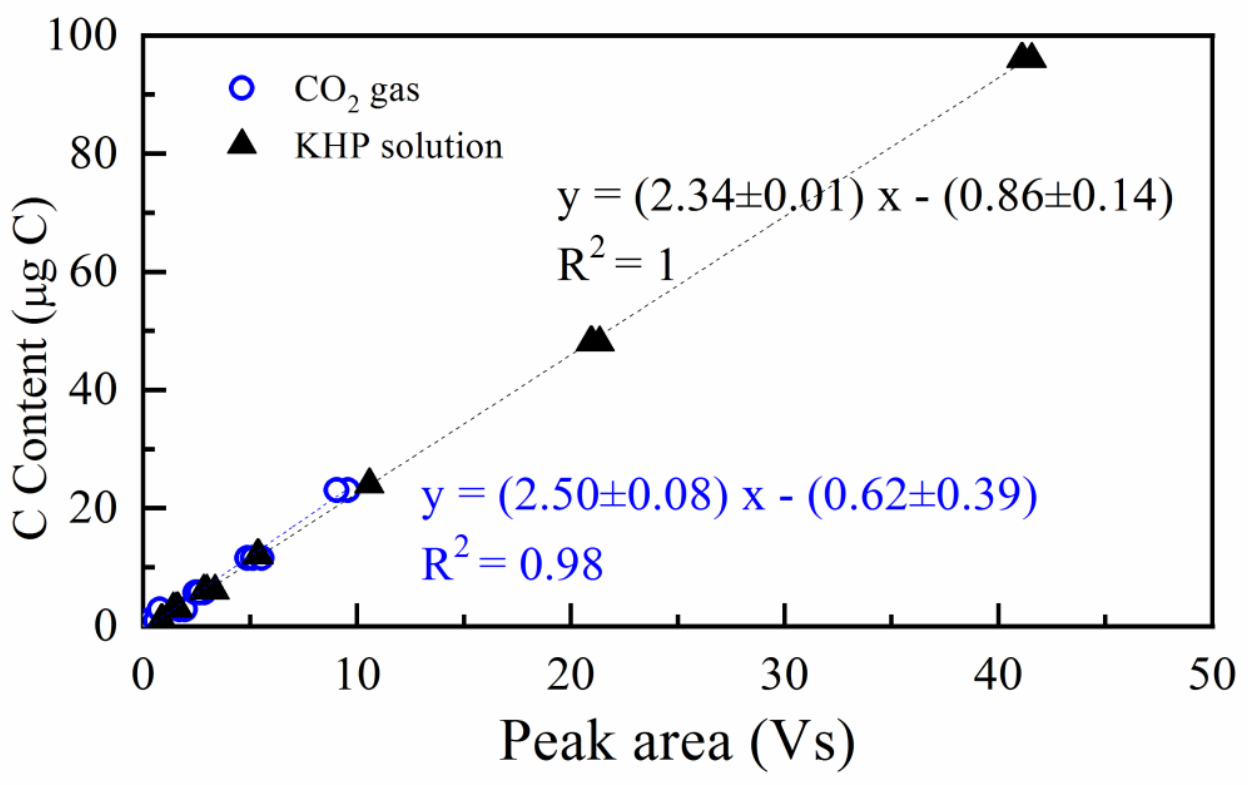

11

Figure S2. Standard curve to quantify the unknown samples.

13 (The standard curve is established by the $\mathrm{CO}_{2}$ gas / the KHP solution and the input carbon content 14 of the certain vials. The blue dotted line is the linear fit of the results of $\mathrm{CO}_{2}$ gas, and the black 15 dotted line is the linear fit of the results of KHP solution.) 


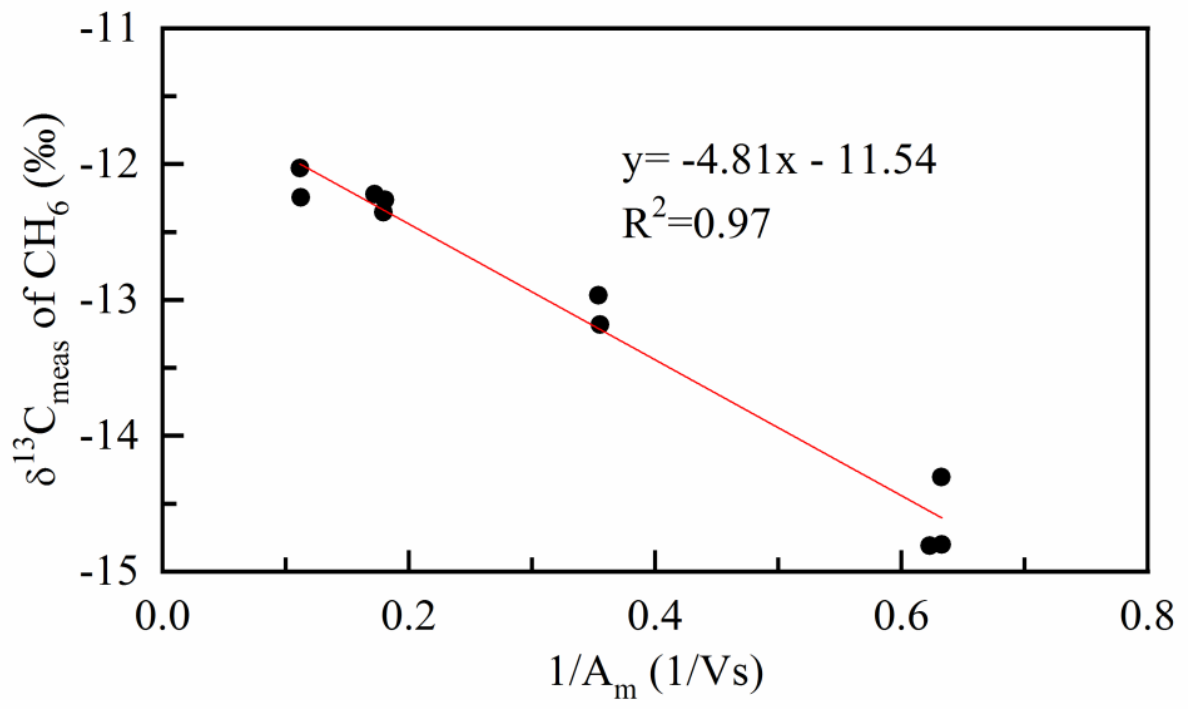

17

18 Figure S3. Relationship between the values of $1 / \mathrm{A}_{\mathrm{m}}$ and $\delta^{13} \mathrm{C}$ obtained from the measurement of $19 \mathrm{CH}_{6}$ 


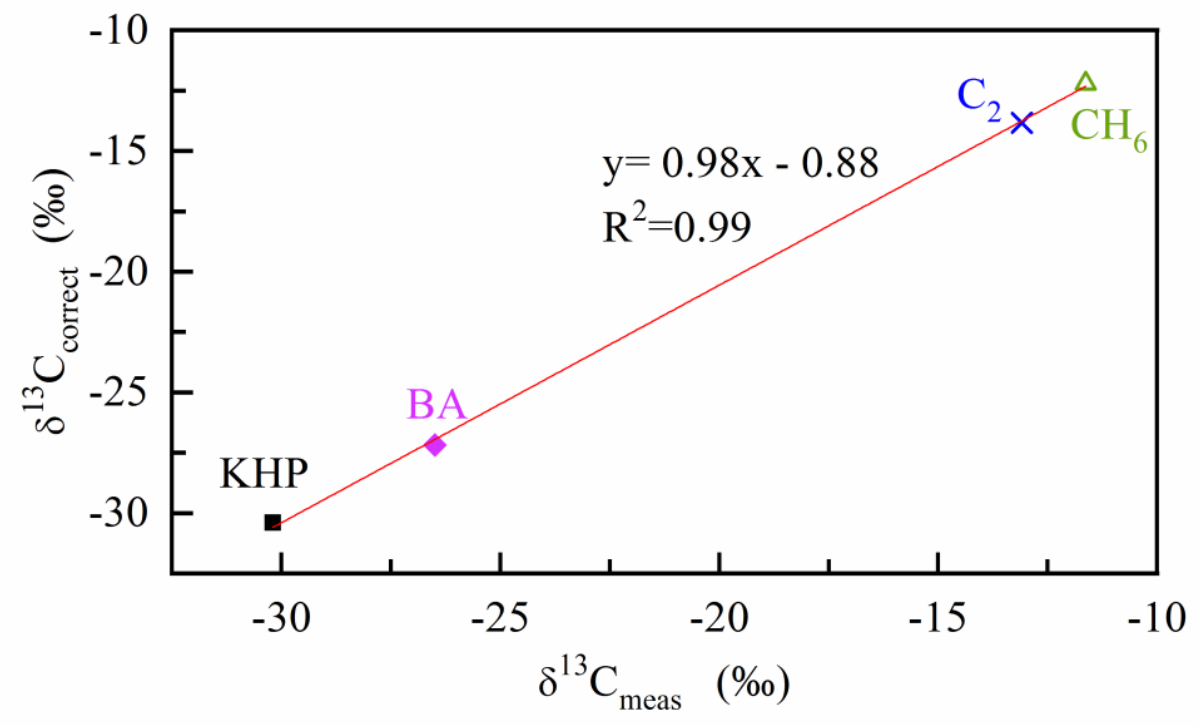

Figure S4. Calibration curve of the isotope composition for the correction of the systematic bias. (The values of $y$ axis are the correct isotope values of the standards measured with EA using combustion method without pretreatment, and the values of $\mathrm{x}$ axis are the measured isotope results of the standards obtained from the wet oxidation method and determined with Gas Bench II.) 


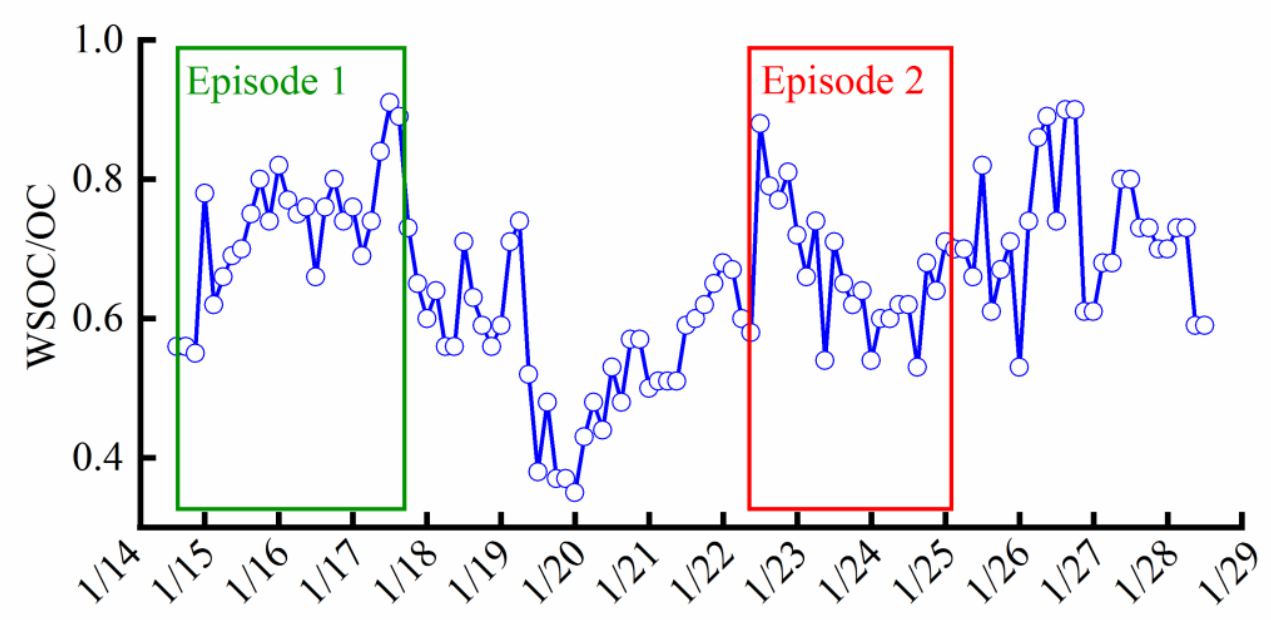

26

27 Figure S5. Time series of WSOC/OC. 